\title{
Molecular profiling of locally-advanced rectal adenocarcinoma using microRNA expression (Review)
}

\author{
CORY PETTIT, STEVE WALSTON, PATRICK WALD, AMY WEBB and TERENCE M. WILLIAMS \\ The Ohio State University Medical Center, Arthur G. James Comprehensive Cancer Center \\ and Richard J. Solove Research Institute, Columbus, OH 43210, USA
}

Received March 6, 2017; Accepted May 9, 2017

DOI: 10.3892/ijo.2017.4045

\begin{abstract}
Treatment for locally-advanced rectal cancer (LARC) typically consists of neoadjuvant chemoradiation followed by total mesorectal excision. Recently, there has been growing interest in non-operative management for patients who are medically-inoperable or wish to avoid surgical morbidity and permanent colostomy. Approximately $50 \%$ of patients who receive pre-operative neoadjuvant chemoradiation develop some degree of pathologic response. Approximately 10-20\% of patients are found to have a complete pathologic response, a finding which has frequently been shown to predict better clinical outcomes, including local-regional control, distant metastasis and survival. Many recent studies have evaluated the role of molecular biomarkers in predicting response to neoadjuvant therapy. MicroRNAs (miRNAs) are an emerging class of biomarkers that have the potential to predict which patients are most likely to benefit from pre-operative therapy and from a selective surgical approach. Here, we review the published literature on microRNAs as prognostic and predictive biomarkers in rectal cancer after pre-operative therapy. In the future, the development of prospectively validated miRNA signatures will allow clinical implementation of miRNAs as prognostic and predictive signatures in LARC.
\end{abstract}

\section{Contents}

1. Introduction

2. Patient studies evaluating miRNAs and response in rectal cancer

3. Summary of individual miRs and in vitro studies

4. IPA Molecular Network Analysis

5. Conclusions/Future directions

Correspondence to: Dr Terence M. Williams, Department of Radiation Oncology, The Ohio State University, 460 W. 12th Avenue, Room 492, Columbus, OH 43210, USA

E-mail: terence.williams@osumc.edu

Key words: miRNA, rectal cancer, radiation, chemotherapy, preoperative chemoradiotherapy, response evaluation, molecular profiling

\section{Introduction}

Colorectal cancer (CRC) is the 3rd most common cancer in men and women in the United States. There are approximately 135,000 new cases of colorectal cancer diagnosed per year (1). Approximately one out of three cases of colorectal cancer is located in the rectum and categorized as rectal adenocarcinoma. Common treatments for localized (nonmetastatic) rectal cancer include surgery, chemotherapy and radiation therapy. Neoadjuvant (pre-operative) chemoradiation has been shown in multiple randomized clinical trials to improve clinical outcomes and toxicity profiles compared to post-operative chemoradiation for locally-advanced rectal cancer. This approach has become the current standard of care, and typically consists of 5-fluorouracil based chemoradiation over 5.5 weeks, followed by total mesorectal excision $6-10$ weeks later $(2,3)$. In $\sim 10-20 \%$ of cases, pathological complete response (pCR) is observed in the surgical resection specimen after neoadjuvant chemoradiation (4-8). In addition, up to $25-50 \%$ of patients develop a clinical complete response (cCR) after neoadjuvant chemoradiation, which is determined by endoscopic or imaging-based assessments (9). The discrepancy between rates of pCR and cCR results from the presence of microscopic tumor deposits which are undetectable using clinical techniques, but are discovered with meticulous pathologic assessment following resection. Notaby, a study published in 2004 showed that for patients who experienced a pCR or cCR after chemoradiation, subsequent surgery had no effect on disease-free survival or cancer control (10). The potential for avoiding surgery, and thereby improving quality of life for these patients, has become an active area of research, particularly in patients who otherwise would require an abdominoperineal resection (APR) and permanent colostomy. Indeed, there have been multiple publications over the last several years highlighting this 'watch and wait' approach, commonly called non-operative management (NOM) or selective surgery (9,11-13). Using this approach, rates of avoiding pelvic surgery in patients treated with definitive chemoradiation have been reported to be as high as $\sim 70 \%$ in some studies, while still maintaining equivalent cancer control (10). Additionally, local control rates remain as high as $95 \%$ with the use of salvage surgery when a local recurrence is detected. While these results are promising, the challenge still remains to prospectively 
identify which patients are best suited for a non-operative approach.

Because less than half of patients experience a $\mathrm{pCR}$ or cCR after chemoradiation, the present study is focused on pre-therapeutic biomarkers that may predict which patients are more likely to achieve a complete response. Many different types of biomarkers have been studied in the hope of identifying patients who would be best treated with a non-operative approach. Many of these molecular profiling studies have focused on DNA, looking for genetic mutations in specific tumor suppressor genes and/or oncogenes, such as APC or TP53, to predict response to therapy. One of the most studied cancer genes is KRAS, a GTPase which is implicated in mediating resistance to the anti-EGFR agent cetuximab (14). KRAS has also been theorized to confer radioresistance, but the results from studies have been mixed. Some studies $(15,16)$ have linked KRAS mutations to lower rates of pCR in patients receiving chemoradiation therapy, while other studies have found that KRAS mutations have no consistent utility in predicting the probability of pCR $(17,18)$. Some articles have postulated that this inconsistency may be due to the fact that mutations specifically in codon 13 of the KRAS gene are also more likely to have concurrent TP53 mutations, potentially explaining why KRAS gene mutations may be associated with radioresistance (since TP53 mutations have also been linked to radioresistance) (19). Other studies have identified other genes such as the DNA repair gene SMC1 (20), the apoptotic gene LUM (21) and the DNA repair gene XRCC3 (22) that predict response to chemoradiation. However, many of these genes are rarely replicated across studies, resulting in the identification of many non-overlapping genes that may predict radiation sensitivity or resistance that is beyond the scope of the present review (23).

Due to the difficulty with identifying genetic aberrations consistently conferring radiation resistance, other genetic biomarkers such as methylation status and non-coding RNA are now being investigated. For example, a 2013 study found that methylation of the TIMP3 gene correlated with chemoradiation resistance (24). In addition, a 2014 study found the expression of long non-coding RNA (lncRNA) lincRNA-p21 to be correlated with improved response to chemoradiation (25). Additional analyses of methylation status and lncRNA biomarkers are ongoing.

In recent years, another type of non-coding RNA, microRNA (miRNA), has been increasingly studied in cancer, along with their possible radio-sensitizing and/or radio-resistant properties. miRNA begins as a DNA transcript called primiRNA in the nucleus, where DGCR8 and Drosha then cut it into pre-miRNA, which subsequently leaves the nucleus (26). In the cytoplasm, an enzyme called DICER cuts the pre-miRNA hairpin into the mature miRNA, which is then loaded onto the RNA-induced silencing complex (RISC). RISC delivers miRNA to particular messenger RNA (mRNA) in order to silence those transcripts. The miRNA binds to the untranslated region of mRNA to prevent it from being able to enter the ribosome and be translated (26). miRNA dysregulation is a well-documented contributing factor to carcinogenesis with loss of normal function resulting in altered expression of important oncogenes and/or tumor suppressor genes (27). Finally, since miRNA can be secreted into bodily fluids with minimal degradation (unlike mRNA), miRNAs have the potential to serve as stable, and relatively non-invasive biomarkers for prognosis and prediction of therapeutic response $(28,29)$.

\section{Patient studies evaluating miRNAs and response in rectal cancer}

In recent years, the role of miRNA dysregulation in cancer has been better elucidated as more studies are identifying particular miRNAs that predict response to treatments such as radiation and chemoradiation. As non-operative management for rectal cancer continues to gain momentum amongst patients and practitioners, it will be especially important to integrate reliable methods of predicting disease response to ensure proper patient selection for this approach. We performed a literature review, and to date, twelve studies have analyzed rectal cancer tumor tissue to evaluate the role of various miRNAs (miRs) in predicting therapeutic response (Table I). The results of these studies are listed in Table I. Each of these studies, except for one, included pathological staging, as it has been shown to correlate with prognosis better than clinical downstaging after pre-operative chemoradiation (30). In addition, the majority of these studies performed unbiased screening of hundreds of miRNAs using various platforms (e.g. TaqMan microRNA, miScript assay, Agilent SurePrint Technology Rel 12.0), rather than studying a few miRNAs in a hypothesis-driven (i.e. a priori) manner. As such, these studies may be confounded by type I error resulting from multiple comparison testing methodology. The only studies that were driven by a priori evaluation of certain miRNAs were the studies by Drebber et al (31) Carames et al (36) and Svoboda et al (45). Many of the miRNAs identified in these studies have been shown to impact DNA damage response, cell cycle and apoptotic signaling pathways. The associations of some of these miRNAs with various protein mediators of these pathways are depicted in Fig. 1.

Summary of patient studies identifying a single pre-therapeutic miRNA associated with response. A number of studies have identified relationships between single miRs and pathological response to chemoradiation. Typically, these studies have measured the relationship between the pre-therapeutic levels of certain miRs and the pathological response to therapy. The first of these studies measured the relationship between miR-145, a miR known to downregulate IRS-1 expression and cellular proliferation and treatment response $(24,31)$. Higher pre-therapeutic miR-145 expression levels correlated with chemoradiosensitivity and more pathological tumor downstaging. Other studies have shown that miR-145 levels are often decreased in colorectal cancer, further supporting its role as a tumor suppressor (32-34). Another study by Ramos et al (35) found pre-treatment miR-21-5p expression to be upregulated in patients who demonstrated an improved pathological response to chemoradiation. This result, however, was contradicted by a study by Carames et al (36) which found that increased miR-21 correlates with worse pathologic response to therapy. A study by D'Angelo et al (37) similarly identified that upregulation of miR-125b correlates with a worse pathological response to therapy. This study is particularly interesting, as it found that high expression levels of both tissue and serum miR-125b 


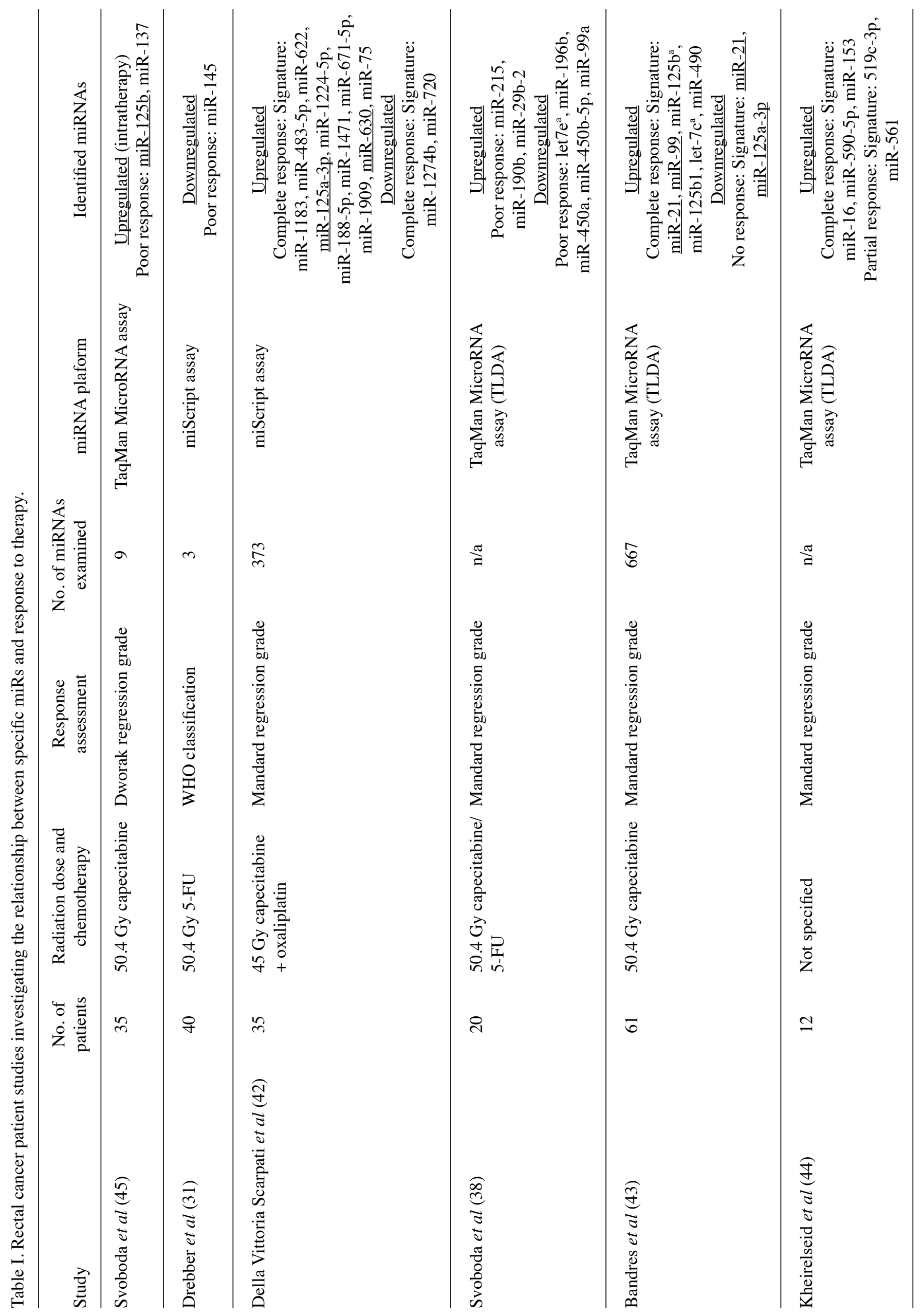




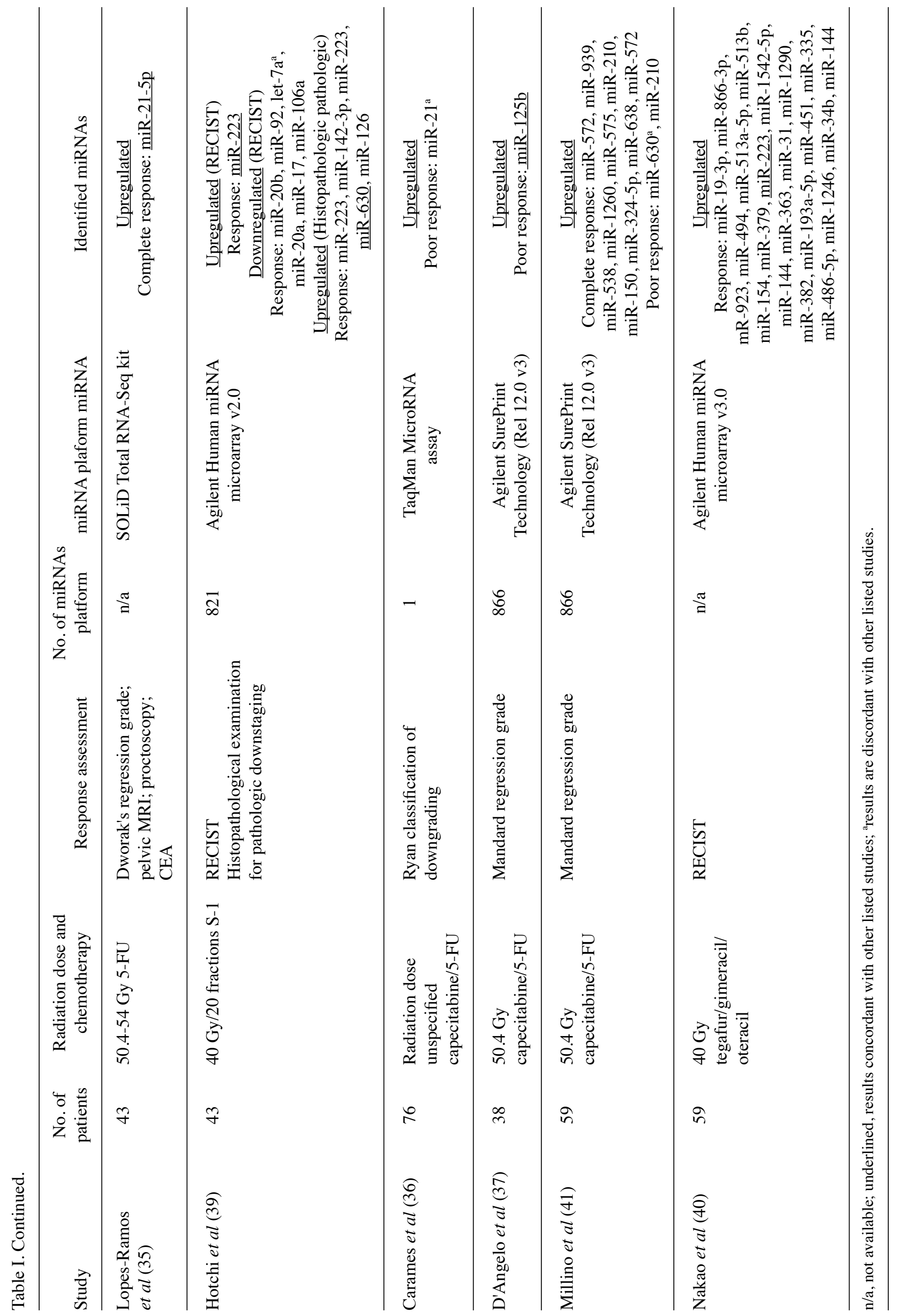




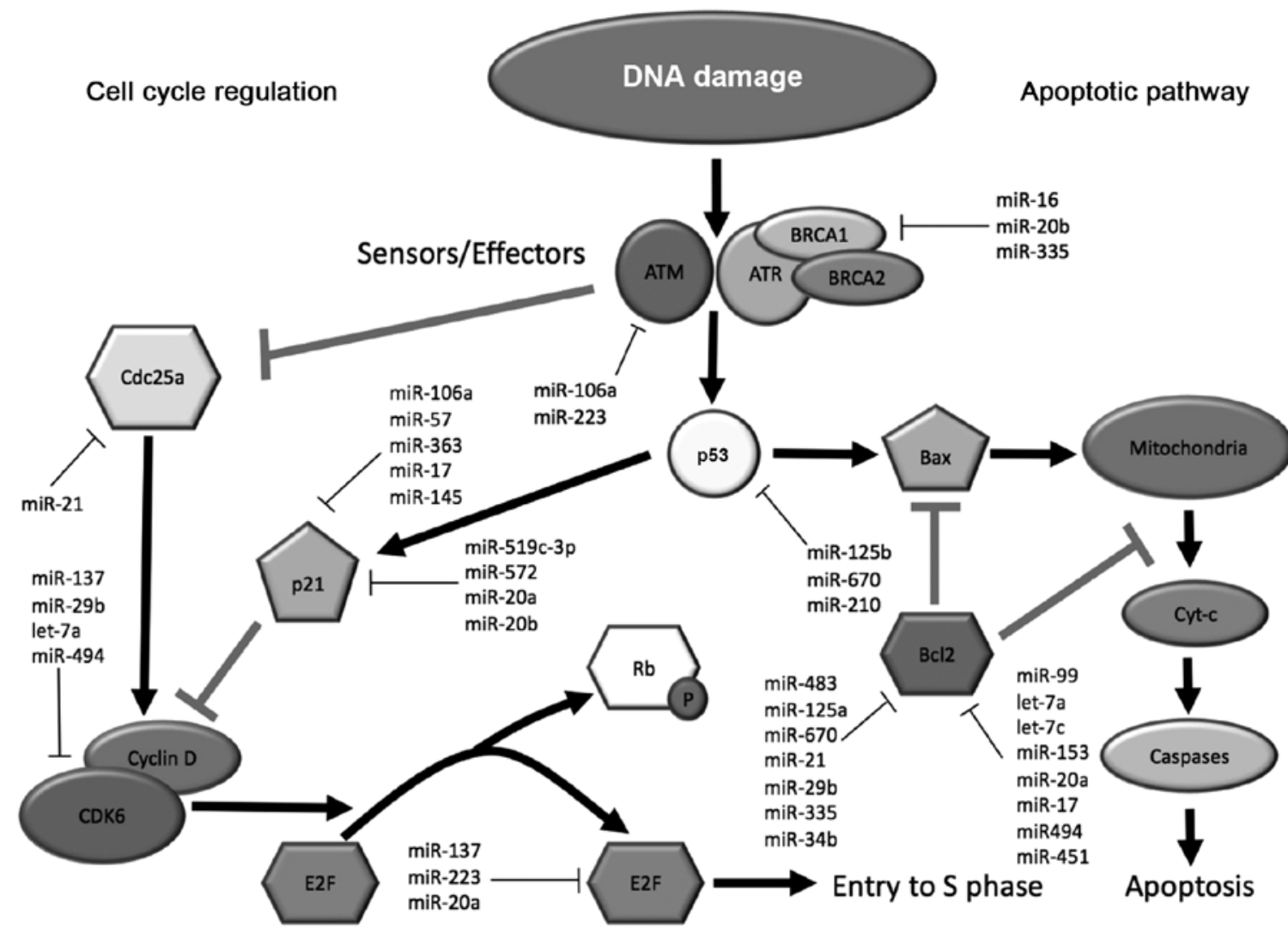

Figure 1. Selected miRNAs from the studies in Table I that act on DNA damage response, cell cycle and apoptosis pathways. The molecular targets of the miRs were found using miRTarBase (http://mirtarbase.mbc.nctu.edu.tw).

correlated with a poor response to therapy. This study supports the potential for serum-based miRNA analysis as a less invasive and cost-effective biomarker compared to tissue-based analysis and offers the potential for serial monitoring.

Summary of patient studies identifying multiple pre-therapeutic miRNAs associated with response. Other studies have identified multiple miRNAs whose individual pre-therapeutic levels correlate with pathological response to chemoradiation. A study by Svoboda et al (38) examining 20 rectal cancer patients detected eight miRNAs that differed in expression between responders and non-responders. Five miRNAs (miR-196b, $450 a, 450 b-5 p$ and $99 a)$ were elevated in responders while three different miRNAs (miR-215, 190b and 29b-2) were elevated in non-responders. A study by Hotchi et al (39) was unique in that it used three separate methods of measuring response to chemoradiation: RECIST (Response Evaluation Criteria in Solid Tumors), histopathological analysis (tumor regression grade) and clinical tumor downstaging. Each of these methods detected distinct miRNAs associated with response to therapy. Using the RECIST method to evaluate response, miR-223 was found to be elevated in responders, while miR-20b, miR-92, let-7a, miR-20a, miR-17 and miR-106a were decreased in responders. Histopathological examination with tumor regression grade revealed miR-142-3p and miR-223 to be elevated in responders. Clinical tumor downstaging showed elevated levels of miR-223, miR-630 and miR-126 to correlate with improved response to therapy. Of these, miR-223 was the only $\mathrm{miR}$ found to be elevated in responders via all three responder classification methods. A study by Nakao et al (40) validated these results by demonstrating that elevated pre-therapeutic miR-223 levels predicted for a pCR. In addition, many other miRs correlated with a complete response, and these can be referenced in Table I. A more recent study by Millino et al (41) found a large number of miRs to be upregulated in complete responders (Table I) They also detected two miRs to be significantly upregulated in non-responders: miR-630 and miR-210. Notably, this finding for miR-630 contradicts studies by Hotchi et al (39) and Della Vittoria Scarpati et al (42).

Summary of patient studies predicting clinical response. As mentioned, pathologic staging appears to correlate better with outcomes than clinical staging and is likely to serve as a better endpoint for development of molecular signatures given that clinical response may be more subjective and that investigators use different methods to assess clinical response (e.g. MRI, PET scan and endoscopic biopsies). However, clinical staging evaluation has the advantage of not requiring a thorough pathologic evaluation of the resected surgical specimen. In addition to the study by Hotchi et al (39), two other studies used clinical/ imaging indicators with or without pathological downstaging to measure response to therapy. Lopez-Ramos et al (35) assessed clinical response by biopsy, rectal examination, pelvic MRI, proctoscopy and CEA levels. miR-21-5p upregulation prior to therapy was found to predict better clinical and pathologic responses to therapy. Nakao et al (40) was the only study that did not combine clinical downstaging with pathologic downstaging. In the present review, associations 
between miRs were based purely on RECIST response, and many miRs were upregulated and associated with complete imaging response, including miR-223, which was identified in the study by Hotchi et al (39) (Table I).

Summary of patient studies that have developed miRNA signatures. Since single molecular aberrations are often unlikely to reliably predict response across a large number of patients, investigators have attempted to develop signatures by incorporating multiple miRs. In doing so, it is hoped that biomolecular signatures will exhibit improved predictive power compared to single miR biomarkers. Bandres et al (43) examined the expression profile of 667 miRNAs in 85 rectal cancer patients. They found a signature consisting of miR-21, miR-99, miR-125b, miR-125b1, miR-let-7c and miR-490 upregulation that was associated with pCR. Conversely, a signature incorporating miR-21 and 125a-3p downregulation was associated with no response to treatment.

Another study by Della Vittoria Scarpati et al (42) identified many different miRNAs that correlated with treatment response and used these miRs to develop a signature that best correlated with pCR. They identified 13 miRNAs (Table I) that were differentially expressed between complete responders versus incomplete responders. The miRNAs with the strongest predictive value for treatment response were miR-630 and miR-622. A study by Kheirelseid et al (44) reported a unique signature consisting of miR-16, miR-590-5 and miR-153 that, when upregulated, predicted for $\mathrm{pCR}$. The authors also identified a signature comprised of miR-519-3p and miR-561 that could predict a better treatment response. Further efforts are warranted to investigate the utility of miR expression signatures in predicting clinical outcomes and validate them across multiple clinical datasets.

Patient studies comparing miRNA levels before and after therapy. All of the previously mentioned studies used pre-therapeutic miRNA levels to predict response to therapy. Notably, only one study by Svoboda et al (45) measured changes in miRNA expression levels after therapy, and how this difference could predict response to therapy. The authors found that two miRs (miR-125b and miR-137) increased in expression during treatment (from tumor biopsy tissue obtained 2 weeks into chemoradiation) and correlated with a poor response to therapy. Overall, there is a lack of studies utilizing this methodologic approach and further work is warranted to explore how the expression of miRNA biomarkers change during and after therapy. These studies could provide a better understanding of how tumor tissue responds to chemoradiation while simultaneously identifying molecular pathways that could mediate resistance (particularly by assessing miRNAs in recurrent or persistent disease).

\section{Summary of individual miRs and in vitro studies}

Despite the large number of studies, a significant confounding factor is that there has been minimal overlap amongst the miRNAs identified as being predictive of treatment response. This may be due to different tumor down-staging criteria, histopathologic regression grading systems, treatment methods and/or patient characteristics (i.e. cancer stage, grade, perineural invasion and lymphovascular space invasion). However, some miRNAs were identified in multiple studies, and the discussion that follows is centered on many of these, along with some of the in vitro evidence that assists to characterize their mechanisms of action in determining response to CRT. We summarize the major findings of individual miRNAs identified in these rectal cancer studies in Table II.

$m i R-21$. miR-21 is significant as it is the most prolific miRNA in patient studies predicting response to CRT. It was found to have a significant correlation with response to therapy in 3 of the 12 studies examined for this analysis $(35,36,43)$, and had a correlation approaching significance in one other study (36). In addition, its molecular targets and oncogene and tumor suppressor properties are well documented in preclinical studies (46-54). Its role in predicting patient response to CRT, however, remains controversial. Two of the above patient studies found upregulation of miR-21 to be correlated with a complete response to CRT $(35,43)$. An in vitro study by LopesRamos et al (35) showed that miR-21-5p upregulation induces radiosensitization by inhibiting SATB1 expression. SATB1 is a gene regulator that is associated with poor outcomes in rectal cancer (55). This inverse relationship between miR-21-5p and SATB1 has also been confirmed in other cancer types (56). In addition, another in vitro study with colon cancer cells found that miR-21 inhibits cdc25a levels, therefore, arresting the cell cycle at the G1/S checkpoint and preventing tumor growth (57).

A potential radiosensitizing property for miR-21 has been contradicted by other studies, however. Carames et al (36) found that patients having upregulated miR-21 experienced worse response to CRT, postulating that miR-21 conferred radioresistance in these patients. This result has been replicated in an in vitro study by Deng et al (46) which demonstrated that inhibiting miR-21 can increase the sensitivity of CRC cells to CRT. Mechanistically, a link between miR-21 and PDCDR, a programmed cell-death protein, has been identified. PDCD4 helps induce apoptosis, and therefore leads to cellular death. Dou et al showed that PDCD4 inhibition rendered rectal cancer cells less likely to commit to apoptosis after radiation therapy, thereby decreasing the sensitivity of cancer cells to radiation therapy (52). Inhibition of PDCDR by miR-21 has also been shown in several other in vitro studies $(47,50,51,53)$.

These seemingly contradictory results may be due, in part, to miR-21 affecting different gene targets under different cellular circumstances. While targeting SATB1 may induce radiosensitivity, targeting PDCD4 may lead to radioresistance. Context dependencies whereby a gene, RNA transcript, protein, or other molecules have both oncogenic and tumor suppressor roles have been identified for many other molecules, and are similarly possible for miRNAs.

Let-7 family. The Let-7 family of miRNAs was implicated in three of the above studies $(38,39,43)$. Svoboda et al $(38)$ found that let-7e downregulation was associated with a poor response to chemoradiation. Bandres et al (43) report similar results, with let-7c upregulation correlating with complete response. Let-7's role in radiation sensitivity has been extensively studied in vitro, although only one study focused on rectal cancer cells. Salendo et al (58) found that let-7g, in addition to other miRs, promotes increased radiosensitivity in rectal cancer cells, 
Table II. Specific miRs that were common among studies: effect on radiation sensitivity and relevant targets.

\begin{tabular}{|c|c|c|c|c|}
\hline miRNA & $\begin{array}{l}\text { Effect on } \\
\text { radiation }\end{array}$ & Relevant target(s) & Function of target(s) & Study/Authors \\
\hline \multirow[t]{2}{*}{$\operatorname{miR}-21$} & Radioresistance & $\begin{array}{l}\text { SABT1: recruits chromatin } \\
\text { remodeling and epigenetic } \\
\text { modifying proteins }\end{array}$ & $\begin{array}{l}\text { Regulation of gene } \\
\text { expression at } \mathrm{G} 1 / \mathrm{S} \\
\text { checkpoint }\end{array}$ & $\begin{array}{c}\text { Kohwi-Shigematsu et al (55) } \\
\text { Kowalzyk et al (56) } \\
\text { Mima et al }(48)\end{array}$ \\
\hline & Radiosensitivity & $\begin{array}{l}\text { PDCD4: a protein which helps } \\
\text { induce apoptosis }\end{array}$ & Apoptosis & \\
\hline $\begin{array}{l}\text { Let-7 } \\
\text { family }\end{array}$ & Radiosensitivity & $\begin{array}{l}\text { RAS: a GTPase in the MAPK } \\
\text { pathway (identified in } \\
\text { other cell lines) }\end{array}$ & $\begin{array}{l}\text { Regulation of growth, } \\
\text { transcription, and } \\
\text { translation }\end{array}$ & $\begin{array}{l}\text { Johnson et al (59) } \\
\text { Weidhass et al (61) }\end{array}$ \\
\hline $\operatorname{miR}-125 a-5 p$ & Radiosensitivity & $\begin{array}{l}\text { Bcl } 2 \text { family: anti-apoptotic } \\
\text { proteins }\end{array}$ & Anti-apoptosis & $\begin{array}{l}\text { Tong et al }(62) \\
\text { Xie et al }(63)\end{array}$ \\
\hline $\operatorname{miR}-125 b$ & Radioresistance & $\begin{array}{l}\text { p53: regulates cell division and } \\
\text { apoptosis }\end{array}$ & $\begin{array}{l}\text { DNA repair induction, } \\
\text { G1/S checkpoint }\end{array}$ & Banzhaf-Strathmann et al (65) \\
\hline miR-99 & Radiosensitivity & $\begin{array}{l}\text { SNF2H/SMARCA5: chromatin } \\
\text { remodeling factor implicated in } \\
\text { DNA repair } \\
\text { mTOR: integrates } \\
\text { signaling pathways to } \\
\text { promote cellular growth } \\
\text { and survival } \\
\text { HOXA1: transcription } \\
\text { factor and proto-oncogene } \\
\text { that regulates anti-apoptotic }\end{array}$ & $\begin{array}{l}\text { DNA repair, cellular } \\
\text { proliferation, survival, } \\
\text { apoptosis }\end{array}$ & $\begin{array}{c}\mathrm{Xu} \text { et al }(68) \\
\text { Tokunaga et al (69) } \\
\text { Hay et al }(70)\end{array}$ \\
\hline miR-630 & Radiosensitivity & $\begin{array}{l}\text { BCL2CL2, TP53RK: proteins } \\
\text { that prevent apoptosis }\end{array}$ & Anti-apoptosis & Zhang et al (73) \\
\hline miR-223 & Radiosensitivity & $\begin{array}{l}\text { STMN1: contributes to mitotic } \\
\text { spindles }\end{array}$ & Exit from mitosis & $\begin{array}{l}\text { Sugatani et al }(74) \\
\text { Fazi et al }(75) \\
\text { Wong et al }(76) \\
\text { Rubin et al }(77) \\
\text { Ghosh et al }(78) \\
\text { Saal et al }(79) \\
\text { Alli et al }(80)\end{array}$ \\
\hline
\end{tabular}

congruent with the Svoboda (38) and Bandres (43) studies. The Salendo study (58) also quantified pre-treatment expression levels of miR-let-7g in rectal cancer biopsy samples and found that higher levels of let-7g were associated with improved disease-free survival.

The possible mechanisms for let-7's radiosensitizing properties can be elucidated via studies in other cancer cell lines. The major target appears to be RAS (59). RAS is a protein in the EGFR/MAPK pathway that has been implicated in diminishing the effectiveness of radiation in multiple cancer types $(60,61)$. Its role in promoting radioresistance appears to be mediated by DNA repair mechanisms, thereby correcting radiation-induced DNA damage and preventing subsequent cell death (61). Let-7 can silence the RAS gene, therefore eliminating this protection and increasing cancer cell susceptibility to radiation therapy. Another study found let-7 to be a master regulator of cell division, possibly affecting more than
30 genes involved in mitosis (59). While very interesting and hypothesis-generating, these studies should be extrapolated to rectal cancer with caution.

A study by Hotchi et al (39) found radioresistance properties associated with a let-7 family member. It showed that let-7a was one of many miRs whose downregulation actually correlated with a complete response. However, this correlation was only seen in one of the three downstaging methods used, and let-7a appears to be the only member of the let-7 family to be associated with radioresistance.

miR-125 family. The miR-125 family was identified in four of the ten patient studies $(37,42,43,45)$. Two of these found upregulated miR-125a-5p levels to be associated with a complete response to therapy. Della Vittoria Scarpati et al (42) found elevated miR-125a-3p to be 1 of 11 elevated miRs implicated in a signature that correlated with complete response to CRT, 
while Bandres et al (43) confirmed this result by finding downregulation of miR-125a-5p to be associated with no response to therapy. Cellular and human tissue studies further confirm these results (62).

A study by Tong et al (62) investigated the cellular targets of miR-125a-5p. In concordance with the two patient studies, they found miR-125a-5p to be a tumor suppressor in colon cancer, inhibiting cell proliferation and growth. Furthermore, they found the anti-apoptotic genes BCL2, BCL2L12 and Mcl-1 to be targets of miR-125a-5p. Increased miR-125a-5p levels decreased the expression of these anti-apoptotic genes, while overexpression of these anti-apoptotic genes overcame the tumor suppressive effect of miR-125a-5p. Additional support for a tumor suppressive role for miR-125a-5p was provided by a study showing miR-125a levels to be decreased in colorectal cancer (63).

These results are distinct from those for miR-125b. miR-125b has been consistently shown to be upregulated in colorectal cancer and correlated with poor prognosis (64). Svoboda et al (45) found elevated miR-125b levels to correlate with a poor response to therapy. This result is supported by a study by D'Angelo et al (37) which found elevated miR-125b levels to correlate with a poor response to chemoradiation. These apparent oncogenic properties of miR-125b were further confirmed by a study by Banzhaf-Strathmann et al (65) identifying the targets of miR-125b to be the apoptosis-associated gene BAK1, as well as cell cycle proteins Puma, cyclin C, $\mathrm{Cdc} 25 \mathrm{c}$ and $\mathrm{p} 53$. The only contradictory study was published by Bandres et al (43) who reported upregulated miR-125b to be part of a miR signature that correlated with complete response.

miR-99. miR-99 was identified in two of the patient studies. Svoboda et al (38) found downregulated miR-99 levels to correlate with a poor response to therapy, and this result was further corroborated by Bandres et al (43) who found that high miR-99 levels correlated with a complete response to therapy. The data may suggest that miR-99 has a radiosensitizing effect. In vitro studies in other cancer cell lines have identified plausible targets for miR-99 that may explain its association with radiosensitization/response. In one study, miR-99 family miRNAs were identified in a screen for miRNAs that correlate with radiosensitivity. They were found to target SNF2H/ SMARCA5 (a SWI/SNF chromatin remodeling factor), reduce BRCA1 localization to sites of DNA damage, and reduce the efficiency of multiple types of double-strand break repair (homologous recombination and non-homologous endjoining) (66). Another study by Sun et al (67) in esophageal cancer cells found that miR-99 induces apoptosis by inhibiting mTOR. mTOR has been identified as an important protein in oncogenesis, as its overexpression and dysregulation leads to uncontrolled proliferation and survival (68). Its functions in cellular growth and proliferation include integration of nutrient sensing pathways and mitochondrial activity (69). mTOR receives extensive signaling input from many upstream cell signaling pathways regulating growth, including insulin and IGF-1 (70). In addition, another study showed that miR-99 family miRNAs target homeobox A1 (HOXA1), a protooncogene, and $\mathrm{Bcl} 2$ and then reduced proliferation, migration and enhanced apoptosis $(69,71)$. Consistent with these func- tions, miR-99 has been shown to be downregulated in human cancers, including prostate, head and neck and esophageal cancer, consistent with tumor suppressive functions (72). Thus, higher miR-99 appears to be associated with improved response.

miR-630. miR-630 was identified in three of the patient studies $(39,41,42)$. Two of these, Hotchi et al (39 and Della Vittoria Scarpati et al (42) found that upregulated miR-630 correlated with a better response to chemoradiation. Additional support for this result was provided by an in vitro study by Zhang et al (73) who found that miR-630 induces apoptosis in cancer cells after radiation therapy. Subsequent mechanistic investigations identified that the targets of miR-630 are BCL2L2 and TP53RK, two proteins which prevent apoptosis. However, these results were contradicted by the most recent study by D'Angelo et al (37), which found that miR-630 upregulation correlates with a poor response to CRT.

$m i R-223$. miR-223 was identified in two of the studies, and in both cases, its upregulation increased response to CRT. In Hotch et al (39), the evidence for miR-223 radiosensitizing effect was especially strong, as it was the only miR to be consistently associated with an increased response in all three methods of response assessment. Nakao et al (40) provided supporting evidence of this, as miR-223 was one of many miRs associated with an increase in response to CRT. No in vitro studies have been performed to examine the mechanism of action of miR-223 in rectal cancer cells specifically, but studies from other cell lines propose a role in modulating cell differentiation and proliferation $(74,75)$. In hepatocellular carcinoma, STMN1 has been identified as a target of miR-223 which is responsible for its tumor suppressor effect (76). STMN1 is a microtubule regulator which promotes depolymerization of tubulin and is important for forming the mitotic spindle. Inhibition of STMN1 leads to cell accumulation in the G2/M phase, unable to exit mitosis (77). In addition, overexpression of STMN1 has been correlated with poor treatment response in other tumor types (78-80). Therefore, the tumor suppressive effects of miR-223 may be mediated by silencing of STMN1, thereby preventing cancer cells from proliferating.

\section{IPA Molecular Network Analysis}

An Ingenuity Pathway Analysis (IPA) was carried out to find potential links between some of the miRs found in the present review. miR-223, miR-21, miR-125a, miR-125b, miR-630, miR-99 and the let-7 family were analyzed. The IPA analysis searched the literature for upstream and downstream targets of these miRs, and then tried to connect them into a single possible network. A network (Fig. 2) was identified containing six of the seven miRs, with an IPA correlation score of 17. One of the main molecules in this network was AGO2, which has been shown to interact with many of the miRs. AGO2 is a member of the argonaute family of proteins which guide miRs to their targets for silencing (81). One important target of this pathway is CDC25A. CDC25A has been identified as an oncogene, encoding for cdc25a, which 


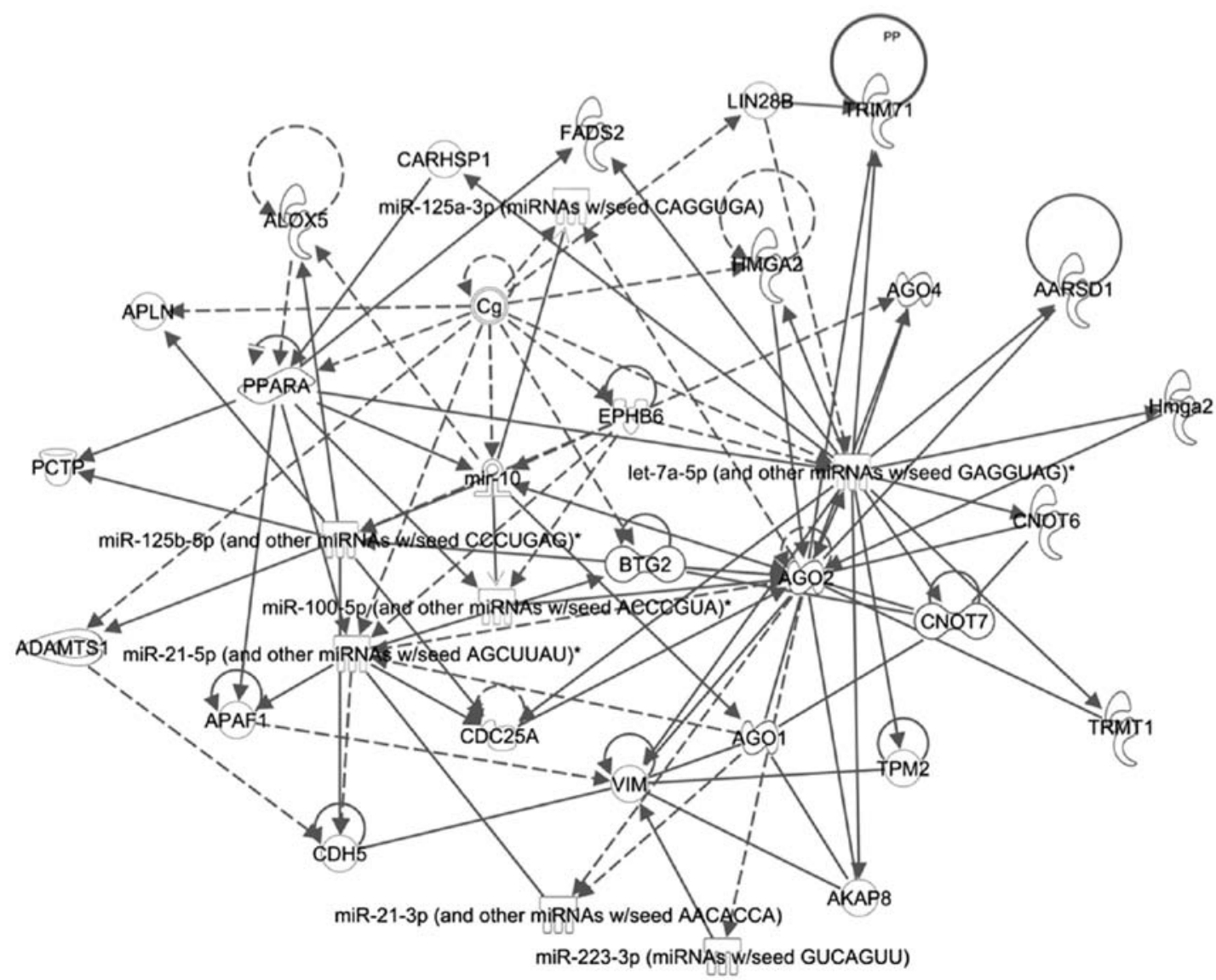

Figure 2. Ingenuity pathway analysis of the miRNAs in Table II: miR-21, miR-125a, miR-125b, miR-99/100, miR-223 and let-7a. Solid lines indicate a direct relationship while dotted lines indicate an indirect relationship.

is required to transition from the $\mathrm{G} 1$ to $\mathrm{S}$ of mitosis $(82,83)$. These results suggest that some of identified miRs may work together to modulate the ability of tumor cells to progress through the cell cycle, and therefore ultimately modify their radiosensitivity.

\section{Conclusions/Future directions}

There are promising results with the use of miRNAs as biomarkers to predict response in rectal cancer after CRT. However, as shown above, there is no consensus among studies with regards to the individual miRs or miR signatures that predict $\mathrm{pCR}$ or $\mathrm{cCR}$. This may be due to many different confounding factors. One is that some studies used different chemotherapy regimens with distinct agents (e.g. fluorouracil, capecitabine, platinum agent and S-1) and/or doses that may induce different miR responses. In addition, the different types of tissue fixation methods that were used (paraffin-embedded versus frozen) might impact results as well. Another potential confounding factor is that the studies used different methodologies to evaluate expression of miRNAs as shown in Table I, certainly leading to variability in quantification. Furthermore, different staging techniques and different endpoints (e.g. clinical response versus pathologic response) may have contributed to some inconsistencies between studies. Finally, performing large-scale molecular testing can be subject to type I error from multiple comparisons testing.
Future studies should attempt to develop and validate consistent miR signatures that correlate with pathological and/ or clinical complete responses, and be cognizant of the endpoint that is being used to develop the signature. For example, if a signature is designed to best select patients for avoiding surgery after neoadjuvant CRT, the quality of the signature should be based on its ability to predict pCR. Conversely, if a signature is being developed to predict a poor response after CRT, then the signature should reliably predict which patients will have lymph node positive disease or poor tumor regression grade (e.g. Mandard TRG $\geq 4$ ) after standard CRT in efforts to potentially intensify the neoadjuvant regimen. Finally, if the clinical objective is to potentially alter post-operative (adjuvant) treatment, the signature should be able to predict local or distant recurrence. Further research should also be focused on developing more predictive signatures using less invasive tests (e.g. urine/serum miRNAs). In addition, other clinical outcomes beyond primary tumor response (e.g. survival, cause-specific survival, colostomy-free survival, local failure, regional failure and distant failure) should ultimately be correlated with miRNA expression. Such predictive biomarkers could then be used to identify patients with a high probability of $\mathrm{pCR} / \mathrm{cCR}$ from chemoradiation, or low probability of response. Ideally, those patients identified as high likelihood of responding could be initially spared the morbidity and quality of life issues associated with total mesorectal excision, particularly for distal tumors. Lastly, miRNA analysis has the potential to identify 
pathways conferring radiation or chemoradiation resistance, by comparing pre-therapeutic and post-therapeutic samples (i.e. at the time of surgery). These analyses hold promise for identifying novel molecular pathways for targeting in combination with radiation or chemoradiation, in an effort to further improve upon current cCR and pCR rates.

\section{Acknowledgements}

The present review was supported by the following grants: the Award Number Grant KL2TR001068 from the National Center for Advancing Translational Sciences, and NIH R01 CA198128 (to T.W.). The content is solely the responsibility of the authors and does not necessarily represent the official views of the National Center for Advancing Translational Sciences or the National Institutes of Health.

\section{References}

1. Siegel RL, Miller KD and Jemal A: Cancer statistics, 2016. CA Cancer J Clin 66: 7-30, 2016

2. Sauer R, Liersch T, Merkel S, Fietkau R, Hohenberger W, Hess C, Becker H, Raab HR, Villanueva MT, Witzigmann H, et al: Preoperative versus postoperative chemoradiotherapy for locally advanced rectal cancer: Results of the German CAO/ARO/ AIO-94 randomized phase III trial after a median follow-up of 11 years. J Clin Oncol 30: 1926-1933, 2012.

3. Roh MS, Colangelo LH, O'Connell MJ, Yothers G, Deutsch M, Allegra CJ, Kahlenberg MS, Baez-Diaz L, Ursiny CS, Petrelli NJ, et al: Preoperative multimodality therapy improves disease-free survival in patients with carcinoma of the rectum: NSABP R-03. J Clin Oncol 27: 5124-5130, 2009.

4. Luna-Pérez P, Rodríguez-Ramírez S, Hernández-Pacheco F, Gutiérrez De La Barrera M, Fernández R and Labastida S: Anal sphincter preservation in locally advanced low rectal adenocarcinoma after preoperative chemoradiation therapy and coloanal anastomosis. J Surg Oncol 82: 3-9, 2003.

5. Hiotis SP, Weber SM, Cohen AM, Minsky BD, Paty PB, Guillem JG, Wagman R, Saltz LB and Wong WD: Assessing the predictive value of clinical complete response to neoadjuvant therapy for rectal cancer: An analysis of 488 patients. J Am Coll Surg 194: 131-135, discussion 135-136, 2002.

6. Habr-Gama A, de Souza PM, Ribeiro U Jr, Nadalin W, Gansl R, Sousa AH Jr, Campos FG and Gama-Rodrigues J: Low rectal cancer: Impact of radiation and chemotherapy on surgical treatment. Dis Colon Rectum 41: 1087-1096, 1998.

7. Medich D, McGinty J, Parda D, Karlovits S, Davis C, Caushaj P and Lembersky B: Preoperative chemoradiotherapy and radical surgery for locally advanced distal rectal adenocarcinoma: Pathologic findings and clinical implications. Dis Colon Rectum 44: 1123-1128, 2001.

8. Grann A, Minsky BD, Cohen AM, Saltz L, Guillem JG, Paty PB, Kelsen DP, Kemeny N, Ilson D and Bass-Loeb J: Preliminary results of preoperative 5-fluorouracil, low-dose leucovorin, and concurrent radiation therapy for clinically resectable $\mathrm{T} 3$ rectal cancer. Dis Colon Rectum 40: 515-522, 1997.

9. Habr-Gama A, Gama-Rodrigues J, São Julião GP, Proscurshim I, Sabbagh C, Lynn PB and Perez RO: Local recurrence after complete clinical response and watch and wait in rectal cancer after neoadjuvant chemoradiation: Impact of salvage therapy on local disease control. Int J Radiat Oncol Biol Phys 88: 822-828, 2014.

10. Habr-Gama A, Perez RO, Nadalin W, Sabbaga J, Ribeiro U Jr, Silva e Sousa AH Jr, Campos FG, Kiss DR and Gama-Rodrigues J: Operative versus nonoperative treatment for stage 0 distal rectal cancer following chemoradiation therapy: Long-term results. Ann Surg 240: 711-717, discussion 717-718, 2004.

11. Renehan AG, Malcomson L, Emsley R, Gollins S, Maw A, Myint AS, Rooney PS, Susnerwala S, Blower A, Saunders MP, et al: Watch-and-wait approach versus surgical resection after chemoradiotherapy for patients with rectal cancer (the OnCoRe project): A propensity-score matched cohort analysis. Lancet Oncol 17: 174-183, 2016.
12. Smith JD, Ruby JA, Goodman KA, Saltz LB, Guillem JG, Weiser MR, Temple LK, Nash GM and Paty PB: Nonoperative management of rectal cancer with complete clinical response after neoadjuvant therapy. Ann Surg 256: 965-972, 2012.

13. Janjan NA, Khoo VS, Abbruzzese J, Pazdur R, Dubrow R, Cleary KR, Allen PK, Lynch PM, Glober G, Wolff R, et al: Tumor downstaging and sphincter preservation with preoperative chemoradiation in locally advanced rectal cancer: The $\mathrm{M}$. D. Anderson Cancer Center experience. Int J Radiat Oncol Biol Phys 44: 1027-1038, 1999.

14. Lièvre $\mathrm{A}$, Bachet $\mathrm{JB}$, Le Corre $\mathrm{D}$, Boige $\mathrm{V}$, Landi $\mathrm{B}$, Emile JF, Côté JF, Tomasic G, Penna C, Ducreux M, et al: KRAS mutation status is predictive of response to cetuximab therapy in colorectal cancer. Cancer Res 66: 3992-3995, 2006.

15. Luna-Pérez P, Segura J, Alvarado I, Labastida S, SantiagoPayán H and Quintero A: Specific c-K-ras gene mutations as a tumor-response marker in locally advanced rectal cancer treated with preoperative chemoradiotherapy. Ann Surg Oncol 7: 727-731, 2000.

16. Duldulao MP, Lee W, Nelson RA, Li W, Chen Z, Kim J and Garcia-Aguilar J: Mutations in specific codons of the KRAS oncogene are associated with variable resistance to neoadjuvant chemoradiation therapy in patients with rectal adenocarcinoma. Ann Surg Oncol 20: 2166-2171, 2013.

17. Davies JM, Trembath D, Deal AM, Funkhouser WK, Calvo BF, Finnegan T, Weck KE, Tepper JE and O'Neil BH: Phospho-ERK and AKT status, but not KRAS mutation status, are associated with outcomes in rectal cancer treated with chemoradiotherapy. Radiat Oncol 6: 114, 2011.

18. Clancy C, Burke JP and Coffey JC: KRAS mutation does not predict the efficacy of neo-adjuvant chemoradiotherapy in rectal cancer: A systematic review and meta-analysis. Surg Oncol 22: 105-111, 2013.

19. Krishnan $\mathrm{S}$ and Chang GJ: KRAS mutations and rectal cancer response to chemoradiation: Are we closer to personalization of therapy? Ann Surg Oncol 20: 3359-3362, 2013.

20. Ghadimi BM, Grade M, Difilippantonio MJ, Varma S, Simon R, Montagna C, Füzesi L, Langer C, Becker H, Liersch T, et al: Effectiveness of gene expression profiling for response prediction of rectal adenocarcinomas to preoperative chemoradiotherapy. J Clin Oncol 23: 1826-1838, 2005.

21. Watanabe T, Komuro Y, Kiyomatsu T, Kanazawa T, Kazama Y, Tanaka J, Tanaka T, Yamamoto Y, Shirane M, Muto T, et al: Prediction of sensitivity of rectal cancer cells in response to preoperative radiotherapy by DNA microarray analysis of gene expression profiles. Cancer Res 66: 3370-3374, 2006.

22. Agostini M, Zangrando A, Pastrello C, D'Angelo E, Romano G, Giovannoni R, Giordan M, Maretto I, Bedin C, Zanon C, et al: A functional biological network centered on XRCC3: A new possible marker of chemoradiotherapy resistance in rectal cancer patients. Cancer Biol Ther 16: 1160-1171, 2015.

23. Conde-Muíño R, Cuadros M, Zambudio N, Segura-Jiménez I, Cano C and Palma P: Predictive biomarkers to chemoradiation in locally advanced rectal cancer. BioMed Res Int 2015: 921435, 2015.

24. Molinari C, Casadio V, Foca F, Zingaretti C, Giannini M, Avanzolini A, Lucci E, Saragoni L, Passardi A, Amadori D, et al: Gene methylation in rectal cancer: Predictive marker of response to chemoradiotherapy? J Cell Physiol 228: 2343-2349, 2013.

25. Wang G, Li Z, Zhao Q, Zhu Y, Zhao C, Li X, Ma Z, Li X and Zhang Y: LincRNA-p21 enhances the sensitivity of radiotherapy for human colorectal cancer by targeting the Wnt/ $\beta$-catenin signaling pathway. Oncol Rep 31: 1839-1845, 2014.

26. Iorio MV and Croce CM: MicroRNAs in cancer: Small molecules with a huge impact. J Clin Oncol 27: 5848-5856, 2009.

27. Volinia S, Calin GA, Liu CG, Ambs S, Cimmino A, Petrocca F, Visone R, Iorio M, Roldo C, Ferracin M, et al: A microRNA expression signature of human solid tumors defines cancer gene targets. Proc Natl Acad Sci USA 103: 2257-2261, 2006.

28. Kosaka N, Iguchi H and Ochiya T: Circulating microRNA in body fluid: A new potential biomarker for cancer diagnosis and prognosis. Cancer Sci 101: 2087-2092, 2010.

29. D'Angelo E, Vicentini C, Agostini M, Kiss A, Baffa R, Scarpa A and Fassan M: MicroRNAs as tools and effectors for patient treatment in gastrointestinal carcinogenesis. Curr Drug Targets 16: 383-392, 2015. 
30. Suárez J, Vera R, Balén E, Gómez M, Arias F, Lera JM, Herrera J and Zazpe C: Pathologic response assessed by Mandard grade is a better prognostic factor than down staging for disease-free survival after preoperative radiochemotherapy for advanced rectal cancer. Colorectal Dis 10: 563-568, 2008.

31. Drebber U, Lay M, Wedemeyer I, Vallböhmer D, Bollschweiler E, Brabender J, Mönig SP, Hölscher AH, Dienes HP and Odenthal M: Altered levels of the onco-microRNA 21 and the tumor-supressor microRNAs 143 and 145 in advanced rectal cancer indicate successful neoadjuvant chemoradiotherapy. Int J Oncol 39: 409-415, 2011.

32. Akao Y, Nakagawa Y and Naoe T: MicroRNAs 143 and 145 are possible common onco-microRNAs in human cancers. Oncol Rep 16: 845-850, 2006.

33. Bandrés E, Cubedo E, Agirre X, Malumbres R, Zárate R, Ramirez N, Abajo A, Navarro A, Moreno I, Monzó M, et al: Identification by real-time PCR of 13 mature microRNAs differentially expressed in colorectal cancer and non-tumoral tissues. Mol Cancer 5: 29, 2006.

34. Iorio MV, Ferracin M, Liu CG, Veronese A, Spizzo R, Sabbioni S, Magri E, Pedriali M, Fabbri M, Campiglio M, et al: MicroRNA gene expression deregulation in human breast cancer. Cancer Res 65: 7065-7070, 2005.

35. Lopes-Ramos CM, Habr-Gama A, Quevedo BS, Felício NM, Bettoni F, Koyama FC, Asprino PF, Galante PA, GamaRodrigues J, Camargo AA, et al: Overexpression of miR-21-5p as a predictive marker for complete tumor regression to neoadjuvant chemoradiotherapy in rectal cancer patients. BMC Med Genomics 7: 68, 2014.

36. Caramés C, Cristóbal I, Moreno V, del Puerto L, Moreno I, Rodriguez M, Marín JP, Correa AV, Hernández R, Zenzola V, et al: MicroRNA-21 predicts response to preoperative chemoradiotherapy in locally advanced rectal cancer. Int J Colorectal Dis 30: 899-906, 2015.

37. D'Angelo E, Fassan M, Maretto I, Pucciarelli S, Zanon C, Digito M, Rugge M, Nitti D and Agostini M: Serum miR-125b is a non-invasive predictive biomarker of the pre-operative chemoradiotherapy responsiveness in patients with rectal adenocarcinoma. Oncotarget 7: 28647-28657, 2016.

38. Svoboda M, Sana J, Fabian P, Kocakova I, Gombosova J, Nekvindova J, Radova L, Vyzula R and Slaby O: MicroRNA expression profile associated with response to neoadjuvant chemoradiotherapy in locally advanced rectal cancer patients. Radiat Oncol 7: 195, 2012.

39. Hotchi M, Shimada M, Kurita N, Iwata T, Sato H, Morimoto S, Yoshikawa K, Higashijima J and Miyatani T: microRNA expression is able to predict response to chemoradiotherapy in rectal cancer. Mol Clin Oncol 1: 137-142, 2013.

40. Nakao T, Iwata T, Hotchi M, Yoshikawa K, Higashijima J, Nishi M, Takasu C, Eto S, Teraoku H and Shimada M: Prediction of response to preoperative chemoradiotherapy and establishment of individualized therapy in advanced rectal cancer. Oncol Rep 34: 1961-1967, 2015.

41. Millino C, Maretto I, Pacchioni B, Digito M, De Paoli A, Canzonieri V, D'Angelo E, Agostini M, Rizzolio F, Giordano A, et al: Gene and microRNA expression are predictive of tumor response in rectal adenocarcinoma patients treated with preoperative chemoradiotherapy. J Cell Physiol 232: 426-435, 2016.

42. Della Vittoria Scarpati G, Falcetta F, Carlomagno C, Ubezio P, Marchini S, De Stefano A, Singh VK, D'Incalci M, De Placido S and Pepe S: A specific miRNA signature correlates with complete pathological response to neoadjuvant chemoradiotherapy in locally advanced rectal cancer. Int J Radiat Oncol Biol Phys 83: 1113-1119, 2012.

43. Bandres E, Arias F, Guerrero D, Lopez I, Gonzalez-Huarriz M, Gomez Dorronsoro ML, Montes M, Monzon F, Torrea N and Pedro Armendariz P: Association between a specific miRNA signature and pathological response to neoadjuvant chemoradiotherapy (CRT) in locally advanced rectal cancer (LARC) patients. J Clin Oncol 30: e14057, 2012.

44. Kheirelseid EA, Miller N, Chang KH, Curran C, Hennessey E, Sheehan M, Newell J, Lemetre C, Balls G and Kerin MJ: miRNA expressions in rectal cancer as predictors of response to neoadjuvant chemoradiation therapy. Int J Colorectal Dis 28: 247-260, 2013.

45. Svoboda M, Izakovicova Holla L, Sefr R, Vrtkova I, Kocakova I, Tichy B and Dvorak J: Micro-RNAs miR125b and miR137 are frequently upregulated in response to capecitabine chemoradiotherapy of rectal cancer. Int J Oncol 33: 541-547, 2008.
46. Deng J, Lei W, Fu JC, Zhang L, Li JH and Xiong JP: Targeting miR-21 enhances the sensitivity of human colon cancer HT-29 cells to chemoradiotherapy in vitro. Biochem Biophys Res Commun 443: 789-795, 2014

47. Asangani IA, Rasheed SA, Nikolova DA, Leupold JH, Colburn NH, Post S and Allgayer H: MicroRNA-21 (miR-21) post-transcriptionally downregulates tumor suppressor Pdcd4 and stimulates invasion, intravasation and metastasis in colorectal cancer. Oncogene 27: 2128-2136, 2008.

48. Mima K, Nishihara R, Yang J, Dou R, Masugi Y, Shi Y, da Silva A, Cao Y, Song M, Nowak J, et al: MicroRNA MIR21 (miR-21) and PTGS2 expression in colorectal cancer and patient survival. Clin Cancer Res 22: 3841-3848, 2016.

49. Chang KH, Miller N, Kheirelseid EA, Ingoldsby H, Hennessy E, Curran CE, Curran S, Smith MJ, Regan M, McAnena OJ, et al: MicroRNA-21 and PDCD4 expression in colorectal cancer. Eur J Surg Oncol 37: 597-603, 2011.

50. Fassan M, Pizzi M, Giacomelli L, Mescoli C, Ludwig K, Pucciarelli S and Rugge M: PDCD4 nuclear loss inversely correlates with miR-21 levels in colon carcinogenesis. Virchows Arch 458: 413-419, 2011

51. Allgayer H: Pdcd4, a colon cancer prognostic that is regulated by a microRNA. Crit Rev Oncol Hematol 73: 185-191, 2010.

52. Li T, Leong MH, Harms B, Kennedy $\mathrm{G}$ and Chen L: MicroRNA-21 as a potential colon and rectal cancer biomarker. World J Gastroenterol 19: 5615-5621, 2013.

53. Chang KH, Miller N, Kheirelseid EA, Lemetre C, Ball GR, Smith MJ, Regan M, McAnena OJ and Kerin MJ: MicroRNA signature analysis in colorectal cancer: Identification of expression profiles in stage II tumors associated with aggressive disease. Int J Colorectal Dis 26: 1415-1422, 2011.

54. Dou X, Wang RB, Meng XJ, Yan HJ, Jiang SM, Zhu KL, Xu XQ, Chen D, Song XR and Mu DB: PDCD4 as a predictor of sensitivity to neoadjuvant chemoradiotherapy in locally advanced rectal cancer patients. Asian Pac J Cancer Prev 15: 825-830, 2014.

55. Kohwi-Shigematsu T, Poterlowicz K, Ordinario E, Han HJ, Botchkarev VA and Kohwi Y: Genome organizing function of SATB1 in tumor progression. Semin Cancer Biol 23: 72-79, 2013.

56. Kowalczyk AE, Krazinski BE, Godlewski J, Grzegrzolka J, Kiewisz J, Kwiatkowski P, Sliwinska-Jewsiewicka A, Dziegiel P and Kmiec Z: SATB1 is down-regulated in clear cell renal cell carcinoma and correlates with miR-21-5p overexpression and poor prognosis. Cancer Genomics Proteomics 13: 209-217, 2016.

57. Wang P, Zou F, Zhang X, Li H, Dulak A, Tomko RJ Jr, Lazo JS, Wang Z, Zhang L and Yu J: microRNA-21 negatively regulates Cdc25A and cell cycle progression in colon cancer cells. Cancer Res 69: 8157-8165, 2009.

58. Salendo J, Spitzner M, Kramer F, Zhang X, Jo P, Wolff HA, Kitz J, Kaulfuß S, Beißbarth T, Dobbelstein M, et al: Identification of a microRNA expression signature for chemoradiosensitivity of colorectal cancer cells, involving miRNAs-320a, -224, -132 and let7g. Radiother Oncol 108: 451-457, 2013.

59. Johnson CD, Esquela-Kerscher A, Stefani G, Byrom M, Kelnar K, Ovcharenko D, Wilson M, Wang X, Shelton J, Shingara J, et al: The let-7 microRNA represses cell proliferation pathways in human cells. Cancer Res 67: 7713-7722, 2007.

60. Sklar MD: The ras oncogenes increase the intrinsic resistance of NIH 3T3 cells to ionizing radiation. Science 239: 645-647, 1988.

61. Weidhaas JB, Eisenmann DM, Holub JM and Nallur SV: A conserved RAS/mitogen-activated protein kinase pathway regulates DNA damage-induced cell death postirradiation in Radelegans. Cancer Res 66: 10434-10438, 2006.

62. Tong Z, Liu N, Lin L, Guo X, Yang D and Zhang Q: miR-125a-5p inhibits cell proliferation and induces apoptosis in colon cancer via targeting BCL2, BCL2L12 and MCL1. Biomed Pharmacother 75: 129-136, 2015

63. Xie B, Ding Q, Han H and Wu D: miRCancer: A microRNAcancer association database constructed by text mining on literature. Bioinformatics 29: 638-644, 2013.

64. Nishida N, Yokobori T, Mimori K, Sudo T, Tanaka F, Shibata K, Ishii H, Doki Y, Kuwano H and Mori M: MicroRNA miR-125b is a prognostic marker in human colorectal cancer. Int J Oncol 38: 1437-1443, 2011.

65. Banzhaf-Strathmann J and Edbauer D: Good guy or bad guy: The opposing roles of microRNA $125 \mathrm{~b}$ in cancer. Cell Commun Signal 12: 30, 2014. 
66. Mueller AC, Sun D and Dutta A: The miR-99 family regulates the DNA damage response through its target SNF2H. Oncogene 32: 1164-1172, 2013

67. Sun J, Chen Z, Tan X, Zhou F, Tan F, Gao Y, Sun N, Xu X, Shao K and He J: MicroRNA-99a/100 promotes apoptosis by targeting mTOR in human esophageal squamous cell carcinoma. Med Oncol 30: 411, 2013.

68. Xu K, Liu P and Wei W: mTOR signaling in tumorigenesis. Biochim Biophys Acta 1846: 638-654, 2014.

69. Tokunaga $C$, Yoshino $K$ and Yonezawa K: mTOR integrates amino acid- and energy-sensing pathways. Biochem Biophys Res Commun 313: 443-446, 2004.

70. Hay N and Sonenberg N: Upstream and downstream of mTOR. Genes Dev 18: 1926-1945, 2004.

71. Chen D, Chen Z, Jin Y, Dragas D, Zhang L, Adjei BS, Wang A, Dai Y and Zhou X: MicroRNA-99 family members suppress Homeobox A1 expression in epithelial cells. PLoS One 8: e80625, 2013.

72. Chen Z, Jin Y, Yu D, Wang A, Mahjabeen I, Wang C, Liu X and Zhou X: Down-regulation of the microRNA-99 family members in head and neck squamous cell carcinoma. Oral Oncol 48: 686-691, 2012.

73. Zhang Y, Yu J, Liu H, Ma W, Yan L, Wang J and Li G: Novel epigenetic CREB-miR-630 signaling axis regulates radiosensitivity in colorectal cancer. PLoS One 10: e0133870, 2015

74. Sugatani T and Hruska KA: MicroRNA-223 is a key factor in osteoclast differentiation. J Cell Biochem 101: 996-999, 2007.

75. Fazi F, Rosa A, Fatica A, Gelmetti V, De Marchis ML, Nervi C and Bozzoni I: A minicircuitry comprised of microRNA-223 and transcription factors NFI-A and C/EBPalpha regulates human granulopoiesis. Cell 123: 819-831, 2005.
76. Wong QW, Lung RW, Law PT, Lai PB, Chan KY, To KF and Wong N: MicroRNA-223 is commonly repressed in hepatocellular carcinoma and potentiates expression of Stathmin1. Gastroenterology 135: 257-269, 2008.

77. Rubin CI and Atweh GF: The role of stathmin in the regulation of the cell cycle. J Cell Biochem 93: 242-250, 2004.

78. Ghosh R, Gu G, Tillman E, Yuan J, Wang Y, Fazli L, Rennie PS and Kasper S: Increased expression and differential phosphorylation of stathmin may promote prostate cancer progression. Prostate 67: 1038-1052, 2007.

79. Saal LH, Johansson P, Holm K, Gruvberger-Saal SK, She QB, Maurer M, Koujak S, Ferrando AA, Malmström P, Memeo L, et al: Poor prognosis in carcinoma is associated with a gene expression signature of aberrant PTEN tumor suppressor pathway activity. Proc Natl Acad Sci USA 104: 7564-7569, 2007.

80. Alli E, Yang JM, Ford JM and Hait WN: Reversal of stathminmediated resistance to paclitaxel and vinblastine in human breast carcinoma cells. Mol Pharmacol 71: 1233-1240, 2007.

81. Völler D, Linck L, Bruckmann A, Hauptmann J, Deutzmann R, Meister G and Bosserhoff AK: Argonaute family protein expression in normal tissue and cancer entities. PLoS One 11: e0161165, 2016.

82. Sexl V, Diehl JA, Sherr CJ, Ashmun R, Beach D and Roussel MF: A rate limiting function of cdc25A for $S$ phase entry inversely correlates with tyrosine dephosphorylation of Cdk2. Oncogene 18: 573-582, 1999.

83. Shen T and Huang S: The role of $\mathrm{Cdc} 25 \mathrm{~A}$ in the regulation of cell proliferation and apoptosis. Anticancer Agents Med Chem 12: 631-639, 2012. 